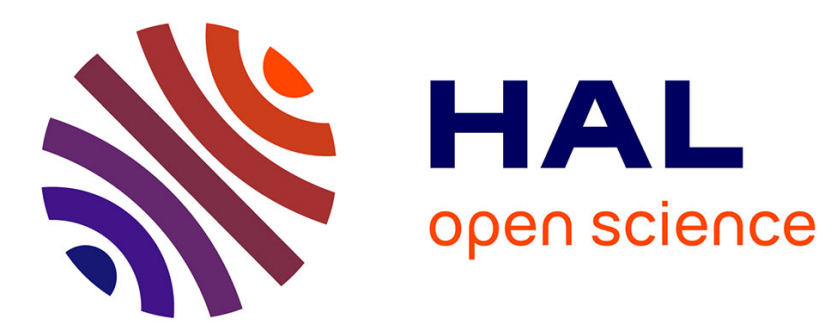

\title{
The anisotropic contact response of viscoplastic monocrystalline ice particles
}

Alexis Burr, Wendy Noël, Pierrick Trecourt, Mathieu Bourcier, Fabien Gillet-Chaulet, Armelle Philip, Christophe L. Martin

\section{To cite this version:}

Alexis Burr, Wendy Noël, Pierrick Trecourt, Mathieu Bourcier, Fabien Gillet-Chaulet, et al.. The anisotropic contact response of viscoplastic monocrystalline ice particles. Acta Materialia, 2017, 132, pp.576-585. 10.1016/j.actamat.2017.04.069 . hal-01864375

\section{HAL Id: hal-01864375 \\ https://hal.science/hal-01864375}

Submitted on 29 Aug 2018

HAL is a multi-disciplinary open access archive for the deposit and dissemination of scientific research documents, whether they are published or not. The documents may come from teaching and research institutions in France or abroad, or from public or private research centers.
L'archive ouverte pluridisciplinaire HAL, est destinée au dépôt et à la diffusion de documents scientifiques de niveau recherche, publiés ou non, émanant des établissements d'enseignement et de recherche français ou étrangers, des laboratoires publics ou privés. 


\title{
The anisotropic contact response of viscoplastic monocrystalline ice particles
}

\author{
Alexis Burr ${ }^{\mathrm{a}, \mathrm{b}}$, Wendy Noël ${ }^{\mathrm{a}}$, Pierrick Trecourt ${ }^{\mathrm{a}, \mathrm{b}}$, Mathieu Bourcier ${ }^{\mathrm{a}}$, Fabien \\ Gillet-Chaulet $^{\mathrm{a}}$, Armelle Philip ${ }^{\mathrm{a}}$, Christophe L. Martin ${ }^{\mathrm{b}}$ \\ ${ }^{a}$ Univ. Grenoble Alpes, CNRS, IRD, IGE, F-38000 Grenoble, France \\ ${ }^{b}$ Univ. Grenoble Alpes, CNRS, Grenoble INP, SIMaP, F-38000 Grenoble, France
}

\begin{abstract}
The contact between two particles of ice is studied experimentally and modeled.

Experiments on the gradual indentation of a single or on two monocrystalline cylinders of ice demonstrate the effect of the relative orientation of their basal planes with the loading axis. Using polarized light and Digital Image Correlation, the main deformation mechanisms are documented. Experimental observations show the strong anisotropy of deformation, with strain localization into shear bands, corresponding to basal gliding of dislocations. When the rotation of cylinders is hindered by a large initial contact size, a simple model is proposed. It is based on indentation theory and takes into account the preferential viscoplastic deformation on the basal plane. The model form is validated by experimental data and by finite element simulations that incorporate the transverse isotropic law of an ice crystal.
\end{abstract}

Keywords: Ice, Contact mechanics, Anisotropy, Digital Image Correlation, Finite Element Method

\section{Introduction}

It has been suggested that dislocation creep is the main deformation mechanism responsible for the densification of firn at low strain-rates $\left(<10^{-5} \mathrm{sec}^{-1}\right)$ [1, 2]. It is taken into account in densification models of firn for which den-

Email address: christophe.martin@grenoble-inp.fr (Christophe L. Martin) 
sity is in the range $0.55-0.84 \mathrm{gcm}^{-3}$ (relative density in the range $0.60-0.92$, $\left.\rho_{\text {ice }}=0.917 \mathrm{gcm}^{-3}\right)[3$, 4. However, some other mechanisms have been also proposed for firn densification. These mechanisms are grain rearrangement, grainboundary sliding, sublimation, recrystallization, volume and surface diffusion [5, 6, 7].

The relative importance of these mechanisms is still an open question and depends on the densification stage considered. A common feature of these proposed mechanisms is that they do not take into account the anisotropic viscoplastic behaviour of an ice crystal . However, Rolland du Roscoat et al. 8, using Diffraction Contrast Tomography on in-situ compression experiments, have demonstrated its importance in the intragranular deformation of large-grained samples during densification. The hexagonal structure of ice makes dislocations slip mainly on basal planes. This leads to a strong viscoplastic anisotropy : for a given applied stress, a crystal of ice deforms approximately $10^{3}$ times faster in the basal plane than in any other planes [9, 10].

Additionally, in the low range of density, the granular nature of snow was recognized very early on by analytical models that represented snow as a collection of grains bonded by solid necks [11. More recently, Theile et al. [7] coupled tomography with Finite Element Modeling, meshing each grain of ice by a beam element. Ice anisotropy was taken into account by the use of orientationdependent material parameters in the flow law. The use of beams was justified by the density range $\left(0.20\right.$ to $\left.0.35 \mathrm{gcm}^{-3}\right)$ studied by the authors, which qualifies the material as low-density snow. In this range of densities, the Discrete Element Method (DEM) is also a tool of choice since it allows the discrete nature of snow to be accounted for. Hagenmuller et al. [12, also proposed to couple tomography reconstructed volumes of snow with simulations. Representing ice particles as rigid clumps of spheres, they showed that the compression behavior of snow is mainly controlled by the actual relative density. Snow densification may also be tackled using homogenization techniques as in [13, where again $\mathrm{X}$-ray tomography images were used as initial microstructures.

At the other extreme of density, for deep dense ice core, the coupling bet- 
ween anisotropy (fabrics) and the state of stress, and their strong impact on ice flow has received much attention (see for example [14, 15, 16]). In particular, the effect of dynamic recrystallization that accommodates deformation is well documented [17.

In between these two extremes, in the intermediate range of relative density (0.60-0.90), the effect of ice anisotropy on the densification of firn has received much less attention. In that density range, firn may be considered as a material that consists of crystallites of ice in contact with each other. Firn bears some important granular characteristics such as grain rearrangement, grain rotation and macroscopic densification under compressive stresses. It may be advantageously modeled as a set of discrete grains that interact with each other through their contacts. The modeling of such a granular packing requires a good understanding of the contact forces that arise upon densification. However, a reliable contact law is still in need to account for the mutual indentation of ice particles. The main ingredients of such a contact law should incorporate viscoplasticity, ice anisotropy, and size effects. Ideally, the contact law should be simple enough to allow for its implementation into an analytical model or a DEM code. Thus, the improvement of current models for firn densification requires the contact mechanics between two grains of ice to be considered in more details, with special attention to anisotropy.

The aim of this paper is to provide a firm experimental basis for the derivation of a simple contact model for ice particles. The article is organized as follows. In section 2 we present a contact model based on indentation theory that incorporates explicitly the viscoplastic anisotropy of an ice crystal. In section 3 the diametrical loading of one or two monocrystalline ice cylinders provides the necessary data to understand the phenomenology of ice particle indentation with particular consideration for anisotropy. This section also presents a partial validation of the model proposed in section 2. Section 4 uses a 2D FEM simulation in which a transverse isotropic law is used to finalize the validation of the analytical model. 


\section{Contact model}

In this paper, we report on experiments focusing on the indentation of monocrystalline ice cylinders and in particular on their anisotropic response. The $\vec{c}$ axis, which defines the cristallographic orientation of an ice crystallite, is perpendicular to the basal plane of the ice hexagonal structure. The elastic behavior of ice is itself anisotropic. The effective Young's modulus varies when it is evaluated about axes that are rotated away from the $\vec{c}$ axis direction. Still, the maximum value (along the $\vec{c}$ axis) is only $30 \%$ larger than the minimum [18]. At the rather high temperatures considered here, elasticity may be neglected. Indeed, ice monocrystals undergo plastic deformation when a shear stress as low as $0.02 \mathrm{MPa}$ is imposed on the basal plane 19, 20. Easy basal slip can occur in the three potential glide directions on the basal plane. Thus the analysis of experimental results uses a constitutive equation that accounts only for the viscoplastic anisotropy of ice crystals 21 by modeling ice as a transversely isotropic medium. It has been shown that this simple model captures the essential features of deforming ice single crystals [22]. Further simplification is achieved in this model by assuming a Newtonian behaviour for the ice crystallite. The literature indicates power-law exponents less than 2.5 for single crystals [9, 10, 20, 23].

The viscoplatic response of the crystal submitted to a uniaxial stress test with axial stress $\sigma$ and axial strain-rate $\dot{\varepsilon}$ writes 21] :

$$
\sigma=2 \mu_{\text {basal }}(4 \alpha-1) f(\theta)^{-1} \dot{\varepsilon}^{n}
$$

where $\mu_{\text {basal }}$ is a material viscosity parameter for shear in the basal plane, $\theta$ is the angle between the $\vec{c}$ axis and the loading axis (Fig. 11), and $f(\theta)$ is a $\frac{\pi}{2}$ periodic function :

$$
f(\theta)=3 \cos ^{4} \theta+2 \alpha \sin ^{4} \theta+\frac{2(4 \alpha-1)-\beta}{\beta} \sin ^{2} \theta \cos ^{2} \theta-\cos ^{2} \theta
$$

where $\alpha$ is the ratio of the axial viscosity along the $\vec{c}$-axis to the axial viscosity normal to the $\vec{c}$-axis; $\beta$ is the ratio of the shear viscosity parallel to the basal plane to the shear viscosity in the basal plane $\left(\mu_{\text {basal }}\right)$. Axial viscosities are 
similar along the $\vec{c}$-axis and the basal plane [22], thus $\alpha$ is approximated in the remaining of this paper to unity leading to a simple expression for $f(\theta)$ :

$$
f(\theta)=2\left(1+3 \frac{1-\beta}{\beta} \sin ^{2} \theta \cos ^{2} \theta\right)
$$

A value $\beta=0.01$ was proposed in [22] to fit, within the approximation of a Newtonian behaviour $(n=1)$, the experimental data obtained on a monocrystalline inclusion embedded in a fine-grained isotropic ice matrix. Whatever its initial crystallographic orientation, the shape of the initially circular inclusion, became ellipsoidal as axial strain increased. The $\beta=0.01$ value allowed for a reasonable agreement between observed and computed evolutions of the deformed ellipse aspect ratio and of the crystallographic orientation.

Figure $1 \mathrm{p}$ shows that the minima of $f(\theta)$ are located at $\theta=0$ and $\theta=$ $\pi / 2$ while the maximum arises for $\theta=\pi / 4$. In other words, the creep rate is maximum when the $\vec{c}$-axis is oriented at $\theta=\pi / 4$ with the axial loading axis. For a given applied stress, Eq. $\left\{3\right.$ shows that the maximum creep rate is $\frac{3+\beta}{4 \beta}$ times the creep rate of the least favorable $\vec{c}$ orientation $(\theta=0, \pi / 2)$. For $\beta=0.01$, this ratio is approximately 75 , indicating the large anisotropy experienced by ice crystallites.

Indentation laws are generally written for spherical particles, taking advantage of spherical symmetries for the derivation. For viscoplastic isotropic materials, Storåkers et al. 24 have for example proposed analytical contact laws that give the indentation load on a spherical body as a function of the viscoplastic material properties. More importantly for the problem treated here, these authors have resolved the contact problem between two dissimilar viscoplastic bodies $i$ and $j$ with constitutive equations of the form :

$$
\sigma=\sigma_{i} \dot{\varepsilon}^{n}
$$

where the material parameter $\sigma_{i}$ pertains to material $i$ but the creep index $n$ is identical for the two materials. Based on indentation theory and on von Mises isotropic flow theory, the indentation load, $N_{v}$, writes for two spherical particles 
of radius $R_{i}$ and $R_{j}\left(R^{*}=R_{i} R_{j} /\left(R_{i}+R_{j}\right)\right)[24,25]$ :

$$
N_{v}=\chi\left(\sigma_{i}^{\frac{-1}{n}}+\sigma_{j}^{\frac{-1}{n}}\right)^{-n}\left(2 R^{*}\right)^{\left(1-\frac{n}{2}\right)} h^{\left(1-\frac{n}{2}\right)} \dot{h}^{n}
$$

where $h$ is the indentation and $\dot{h}$ is the normal rate of approach of the two particles and $\chi$ is a geometric factor with no unit. $N_{v}$ is positive in compression $(\dot{h}>0)$. For two particles $i$ and $j$, which $\vec{c}$ axis make angles $\theta_{i}$ and $\theta_{j}$ with the contact normal, the formulation of Storåkers et al. applied to Eq. (1) leads to :

$$
N_{v}=2 \chi \mu_{\text {basal }}(4 \alpha-1)\left(f\left(\theta_{i}\right)^{n}+f\left(\theta_{j}\right)^{n}\right)^{-n}\left(2 R^{*}\right)^{\left(1-\frac{n}{2}\right)} h^{\left(1-\frac{n}{2}\right)} \dot{h}^{n}
$$

Eq. [6] is the general contact law of two particles which anisotropic behaviour is given by Eq. (1). Now specializing the problem to a Newtonian material and for two particles of identical radius $R$ and a small indentation $(h \ll R)$, the contact radius, $a$ (Fig. 1), may be approximated by :

$$
a^{2}=R h
$$

Introducing the area of contact, $A=\pi a^{2}$, Eq. (6) rewrites $(\alpha=1)$, :

$$
N_{v}=6 \chi \mu_{\text {basal }}\left(f\left(\theta_{i}\right)+f\left(\theta_{j}\right)\right)^{-1}\left(\frac{A}{\pi}\right)^{1 / 2} \dot{h}
$$

The aim of this work is to analyze the applicability of Eqs. (3) and (8) to the indentation problem of two ice particles having arbitrary $\vec{c}$ orientations. The general formulation of Storåkers et al. 25] applies to an indenter of arbitrary profile. However, Eq. (6) has only been derived for axisymmetric contact conditions (typically spheres or flat punches). From an experimental point of view, it is too complex a task to machine or form spherical monocrystalline ice particles. Instead, for practical reasons, we opt for cylindrical geometry. The full derivation of Storåkers et al. formulation for the problem of two indenting cylinders is beyond the scope of this paper (see [26] for the elastic problem of two identical indenting cylinders). Still, we aim at evaluating the suitability of Eq. (8) to the 2-dimensional problem of two cylinders indenting each other and forming a contact of radius $a$ and area of contact $A=2 a L$ with $L$ the cylinder length. The rationale for cylinders also rests on the pluses of a $2 \mathrm{D}$ configuration, which 
allows the propagation of basal slips to be visualized by polarized light (section 3.2 , and strains to be quantified by Digital Image Correlation (section 3.3). These observations would be much more difficult with spheres. Finite Element simulations using the open source code Elmer/Ice [27] complement the experimental investigation and allow for a direct comparison with Eq. (8). These simulations are carried out on a cylindrical geometry (section 4).

\section{Experimental indentation of ice cylinders}

\subsection{Methods}

Diametrical loading tests were carried out either on a single cylinder or on two cylinders (Fig. 2). Cylinders (diameter : $20 \mathrm{~mm} \pm 0.05 \mathrm{~mm}$, length : $8 \mathrm{~mm}$ $\pm 0.05 \mathrm{~mm}$ ) were made of single crystals of ice, which were slowly grown in a crystallizer on top of a cooling device [28. The $\vec{c}$ axis is parallel to the planar faces of the cylinder (the out-of-plane scatter is $\pm 2^{\circ}$ ) to ensure plane stress conditions. The out-of-plane strain $\left(\varepsilon_{x x}\right)$ is negligible. Various $\theta$ angles were selected to investigate the effect of the crystal orientation on the viscoplastic contact behavior. The creep test set up is detailed in Mansuy et al. 29, 30, and is sketched in figure 2. A constant load was applied on the diameter of the samples and the maximum applied load $(109 \mathrm{~N} \pm 1 \mathrm{~N})$ was small enough to avoid fracture. Tests lasting typically five hours were carried out in a cold room at $-10{ }^{\circ} \mathrm{C}\left( \pm 1^{\circ} \mathrm{C}\right)$.

Ice samples are placed between two plates of glass to avoid sublimation and to ensure plane strain conditions. Horizontal black marks allow the samples to be correctly positioned during the tests. Crossed polarizers were used to follow the evolution of basal slips. Images were recorded and analyzed by ImageJ [31] to compute logarithmic strains and rotations. The error on strain was evaluated to be of the order of $0.3 \%$ for the single cylinder configuration, and less than $0.1 \%$ for the two-cylinders configuration. For some tests with two cylinders, both cylinders were truncated to mimic indented particles and to limit rotation of the 
$\vec{c}$ axis during loading. The initial configuration is characterized by the ratio $\frac{a_{0}}{R}$, where $2 a_{0}$ is the initial length of the truncated contact (Fig. 22 ).

Some of the two-cylinders configuration experiments were analyzed by Digital Image Correlation (DIC) to quantify the strain field. The surface of ice samples was slightly scratched with glass paper and a speckle (shoe polish) was applied to obtain a proper grey level and a sufficient contrast for the DIC analysis. A correct light-level was obtained by using two LED lamps with the advantage of limiting brilliance, enabling sufficient contrast and avoiding shadows. This method was already successfully used on polycrystalline ice by Grennerat et al. [32] and recently by Chauve et al. [33. Strain fields are extracted using the CMV software [34] using a plane strain hypothesis. Details on strain calculations can be found in [35]. Integration schemes number 2 or 3 were chosen [34, 35] to ensure a correct identification of local strains with good accuracy. Biquintic subpixel optimization was performed to improve the final correlation output.

\subsection{Diametrical loading on a single cylinder}

Polarised light allows for the observation and the identification of the deformation by basal slips. A color evolution near the contact is detected when deformation initiates in the sample (Fig. 33. The deformation is strongly heterogeneous. However, because test conditions are symmetric, heterogeneities are also symmetric with respect to the cylinder center. The strain is localized in slip bands along basal planes. Two perpendicular lines appear for each contact point in red, contrasting with the undeformed green color. Slip lines are propagating through the crystal perpendicularly to the $\vec{c}$-axis direction (Fig. 3). The bottom contact in Images (A2) and (A3) could indicate an additional slip line parallel to the $\vec{c}$-axis direction. However, a closer examination reveals that these patterns are in fact short slip lines that develop perpendicular to the $\vec{c}$-axis. These lines fully develop in images (A4) and (A5).

Since the basal plane provides only two independent systems, additional degrees of freedom are necessary to accommodate arbitrary loading. In ice, non- 
basal planes are seldom activated, thus requiring other mechanisms [19]. For example, recent studies [33, 36] emphasized that recrystallisation could occur even at low strain (less than $1 \%$ ) or low stress $(0.5 \mathrm{MPa})$ at grain boundaries and triple junctions of polycrystalline ice. Moreover, despite being commonly observed in hexagonal metals, twinning is excluded in ice. Kink and bending bands on the other hand can appear and were observed by Mansuy et al. on polycrystalline ice deformed with our experimental set up [30, 37. In our loading conditions, the cylinder has few constraints and can deform easily by shear on basal planes except for specific values of $\theta\left(0^{\circ}\right.$ and $\left.90^{\circ}\right)$. This peculiar condition is well illustrated by sample $\mathrm{C}$ in Fig. 3 . For all other $\theta$ values the cylinder can deform freely. Melting is another candidate for strain accommodation. It may have occurred as large stress concentration may develop below the contact points. The melting point temperature decreases by about $0.1^{\circ} \mathrm{C}$ for every $1 \mathrm{MPa}$ [10]. A $100 \mathrm{MPa}$ stress would thus be necessary to trigger melting under contacts at $-10^{\circ} \mathrm{C}$.

In any case, all these mechanisms (recrystallisation, kink and bending bands, and melting) would have left a clear signature that was not observed with polarised light. Note that bright spots at contact points on sample B are linked to an image contrast enhancement processing. Hence, dislocation motion on $\{0001\}$ planes should be the main strain accommodation mechanism in our experiment. This should mainly occur by screw dislocations with Burgers vector $\left(\frac{a}{3}\right)<11 \overline{2} 0>$ as these are the least energetic dislocation lines [19]

We observed a clear evolution of the orientation of the $\vec{c}$-axis during the test (Fig. 3). Whatever the $\theta$ value, the $\vec{c}$-axis rotates towards the loading direction in agreement with the compression of a single crystal [38. For example, crystal (A) has rotated by approximately $10^{\circ}$ between its initial state (A1) and its (A5) state . In accordance with crystal anisotropy, strain is primarily limited when the $\vec{c}$-axis is perpendicular or parallel to the loading direction as shown by sample $(\mathrm{C})$.

Fig. 4 a quantitatively confirms the qualitative observations of Fig. 3. Fig. 4 a plots the rotation $\Delta \theta$ of the $\vec{c}$-axis angle against time for all tested samples in 
the single-cylinder configuration. Relative uncertainties are shown only for the $60^{\circ}$ curves but are representative of the other curves (typically $\Delta(\Delta \theta)<4^{\circ}$ ). Significant rotation is observed for samples with loads of the order of $100 \mathrm{~N}$ as demonstrated by Fig. 3 . For these samples, basal glide propagates from the contact point (CP) through the whole cylinder. This is due to the heterogeneous stress field around CP and to the strong ice crystal anisotropy. Note that the two samples corresponding to $\theta=0^{\circ}$ and $\theta=90^{\circ}$ lead to $\Delta \theta=0^{\circ}$ even for very long times (Fig. 3) .

Fig. 5 sketches the proposed main deformation mechanisms encountered for small and large initial $\theta$ angles. Cylinders are sheared by two localized bands to form three different fragments. The central fragment is contained between the contact points and the first basal planes that shear (Fig. 3). The three fragments differ in size depending on initial $\theta$ angle. The central fragment contains all the planes that are gliding during the deformation. The other two fragments are simply pushed away by the rigid planes. For small $\theta$ values, two small caps quickly form. This is illustrative of sample (A) in Fig. 3. In that case, the rotation initiates early (Fig. 4a) but saturates further on since the small cap hinders rotation. For large $\theta$ values, two large caps gradually form. This is illustrative of sample (B) in Fig. 3. The rotation takes more time to initiate since dislocations need to propagate on a larger distance along the large cap. Once initiated, the rotation is facilitated by the geometry of the two large caps. Thus, the $\vec{c}$-axis rotates towards the loading direction. In that final configuration, the fragments get stuck and there is no more driving force for rotation. Therefore, the rotation reaches its maximum and stays constant with time.

Fig. 40 shows the strain evolution in the loading direction $z$. It follows a pattern which is very similar to the pattern of Fig. 怕. It indicates that for a $\vec{c}-$ axis oriented parallel $\left(\theta=0^{\circ}\right)$ or normal $\left(\theta=90^{\circ}\right)$ to the loading axis, no strain is observed although a non-negligible load $(50 \mathrm{~N})$ is applied. We observed that those samples exhibited less than $1 \%$ of axial strain even after more than 17 hours. Similarly, those sample exhibited negligible rotation. Fig. 4 a and b also demonstrate the effect of the applied load intensity with increasing rotation and 
strain for increasing loads for a given $\theta$ value.

\subsection{Diametrical loading on two cylinders}

Tests carried out with the two-cylinders configuration are in qualitative agreement with the observations gathered on the single cylinder configuration. For this configuration, we were able to evaluate the full strain field by DIC on the face of the two cylinders (Fig. 6). In particular, it is possible to obtain the shear strain in the basal plane $\left(\varepsilon_{b c}\right)$. The $\theta$ values of each sample were selected using polarized light outside the set-up. Once installed in the set-up, these values were confirmed by the observation of the basal plane angles, which are assumed to correspond to the maximum shearing. This hypothesis is validated by the very small values of the diagonal components of the strain tensor in the crystallographic axes reference $(\vec{b}, \vec{c})$, such as $\varepsilon_{c c}$ as illustrated in Fig. 6a. These low eigenvalues of strain obtained by DIC are associated to the resolved shear stress needed to activate non-basal glide, which is 60 times greater than for the basal plane activation for the same strain rate [9, 10].

As already observed in the single-cylinder configuration, Figs. 6b-d show strong heterogeneities in shear strain. These figures illustrate that shearing in localized bands becomes very large with increasing strain. For example, Fig. 61 shows that the maximum value of the shear strain in the basal plane $\varepsilon_{b c}$ at $200 \mathrm{~min}$ is more than $40 \%$, while the macroscopic strain $\varepsilon_{z z}$ is only $10 \%$.

We observed that for small strains the cylinder with the most disorientated $\vec{c}$-axis ( $j$ cylinder) consistently exhibits localized shear strain around its contact with the other cylinder (Fig. 6b). For larger strains, heterogeneities that start from loaded contact points or from the extremities of the neck rapidly overthrow any other heterogeneities (Figs. 6e-d).

For the top cylinder $(i)$, which exhibits a small $\theta$ angle, we observed that a strong shear band always develops from the contact with the rigid plane. The maximum shear strain is consistently larger in the small $\theta$ angle cylinder as compared to the maximum shear strain in the large $\theta$ angle cylinder. The width of the shear band in cylinder $i$ is clearly larger than the one of the bottom 
cylinder $j$. This is in agreement with experiments involving only one cylinder where we observed large peripheral fragments for large $\theta$ angles. This confirms that the size of the shear bands depends primarily on the $\vec{c}$-axis orientation, whatever the configuration.

Fig. 7 groups the rotation $\Delta \theta$ of the $\vec{c}$-axis angle against time for samples tested either with point contact between the two cylinders $\left(\frac{a_{0}}{R}=0\right)$ or with finite contact size $\left(\frac{a_{0}}{R}=0.2,0.32,0.35\right)$. The imposed load for all samples is $54 \mathrm{~N}$. Fig. 7 only plots $\Delta \theta$ for the cylinder that experiences maximum rotation but the same qualitative conclusions can be drawn for others. Although error bars on $\Delta \theta$ are rather large (Fig. 4a), machining an initial finite neck size tends to decrease the ability of cylinders to rotate. This may reflect a more realistic state for which multiple contacts between ice crystals exist in the firn. Such contacts would have enlarged over time through sintering mechanisms and viscoplastic deformation to form necks with finite size.

\subsection{Neck size effect}

When rotation is hindered by an initially large neck size, Eq. (8) should allow for a simple relation between strain and load for a given set of angles $\theta_{i}$ and $\theta_{j}$. In this section, we show that experimental data on truncated cylinders support such a relation. For small axial strain $\varepsilon_{z z}$, the initial area of contact $A_{0}=2 a_{0} L$ is assumed to remain constant and the ratio of actual to initial indentation is :

$$
\frac{h}{h_{0}}=1+2 \frac{R}{h_{0}} \varepsilon_{z z}
$$

with $\varepsilon_{z z}$ positive in compression. Integrating between times 0 and $t$ for a constant load test (creep), Eq. (8) leads to :

$$
\varepsilon_{z z}\left(\frac{a_{0}}{R}\right)^{1 / 2}=\frac{\left(f\left(\theta_{i}\right)+f\left(\theta_{j}\right)\right)\left(\frac{\pi}{2}\right)^{1 / 2}}{12 \chi \mu_{\text {basal }} R^{3 / 2} L^{1 / 2}} N_{v} t
$$

Fig. 8 plots the product $\varepsilon_{z z}\left(\frac{a_{0}}{R}\right)^{1 / 2}$ against time for three tests with $\frac{a_{0}}{R}=$ $0.2,0.32,0.35$ for a given load $(53 \mathrm{~N})$ and a given set of angles $\theta_{i}\left(\theta_{i}=30^{\circ}\right.$, $\left.\theta_{j}=65^{\circ}\right)$. Fig. 8 shows that the three tests fall on a master curve for small 
strains (or times). For times smaller than $80 \mathrm{~min}$, the master curve exhibits a linear portion. Using the slope of this linear portion, Eq. 10 , which is only valid for small strains, allows for an estimation of the product $\chi \mu_{\text {basal }}$. Experimental data points lead to $\chi \mu_{\text {basal }} \approx 410^{12}$ Pas. Although the exact value of the geometric parameter $\chi$ is difficult to ascertain for two cylinders, we note that for two indenting Newtonian spheres, $\chi \approx 2[24]$. The viscosity $\mu_{\text {basal }}$ at $-10{ }^{\circ} \mathrm{C}$ may be estimated from the literature for the stress range of interest here at the contact $(0.1-10 \mathrm{MPa})$. It is of the order of 0.5 to $5.10^{12} \mathrm{Pas}$ [9, 22, and thus in good accordance with the value of the product $\chi \mu_{\text {basal }}$ found here. In the following an approximate basal viscosity $\mu_{\text {basal }}=110^{12} \mathrm{Pas}$ is chosen.

\section{Comparison between 2D FEM simulations and experiments}

The aim of this section is to complement the experimental validation of Eq. (8) by specifically investigating the effect of the $\theta$ angle on the normal force at the contact. The Finite Element Method (FEM) with the Elmer/ice opensource code was used to simulate some of the experiments with two truncated cylinders. The model implemented in Elmer/Ice solves the Stokes equations, i.e. neglecting inertial terms, with the full transverse isotropic law of an ice crystal as proposed by Meyssonnier and Philip [21. It simplifies to Eq. (1) for a uniaxial stress state of compression. In accordance with the analytical model, the values of parameters $\alpha$ and $\beta$ are set to 1 . and 0.01, respectively. Gillet-Chaulet et al. 39 have studied the effect of those parameters on the flow response of ice. Details on the model and on the numerical methods can be found in [40, 41].

Here, we use the initial angle orientation of the two $\vec{c}$ vectors defining the contacting cylinders as input, together with the geometry of the truncated contact. Cylinders were meshed using triangular elements with approximate size of $0.5 \mathrm{~mm}$. No specific mesh refinement was used close to the contact zone. A displacement is imposed on the upper boundary to obtain a compressive force $(54 \mathrm{~N})$ with no lateral constraint. Note that neither the cylinder geometry nor the crystallographic orientation evolve for a given simulation. 
Fig. 9 shows the comparison between the FEM simulated and the DIC computed strain-rate fields. Since $\vec{c}$ vectors are given as input to the Elmer/ice code, the orientation of the shear bands coincides with the experimental one, as it should. More interestingly, FEM simulations predict satisfactorily the position and the width of the shear bands as compared to the DIC results. In particular, the FEM simulations reproduce the significant effect of the contact on the spreading of the shear band. For example, considering the bottom cylinder, the shear band starts from point $A$ and develops leftward until it encounters contact point $B$. This shear band is relatively thick due to the combination of geometrical and orientation constraints. In contrast, the shear band on the top cylinder is much thinner due to the $\vec{c}$ axis being nearly perpendicular to the load axis. Note that for the two bands, the strain-rate value becomes null at the extremities of the contact.

Since DIC strain rates are calculated using incremental calculation of a strain map over time, they are far less resolved than strain maps which are calculated from the initial configuration (Fig. 6). Thus, the comparison between FEM simulations and experimental strain rate is merely qualitative. However, the strain-rate magnitudes of FEM and DIC are in reasonable agreement for the chosen value $\mu_{\text {basal }}=110^{12} \mathrm{Pas}$.

A second set of FEM simulations was carried out to confirm the validity of the analytical formulation proposed in Eq. 8). FEM calculations were performed for two truncated cylinders with various pairs of $\left(\theta_{i}, \theta_{j}\right)$ angles for four values of $\frac{a_{0}}{R}(0.141,0.2,0.3,0.4)$. Fig. 10 plots the adimensional rate of approach of the two cylinders obtained by FEM simulations :

$$
\tilde{\dot{h}}=\frac{A_{0}^{1 / 2} \mu_{\text {basal }}}{N_{v}} \dot{h}
$$

Using Eq. 8), the analytical expression of $\tilde{\dot{h}}$ rewrites :

$$
\tilde{h}=\frac{f\left(\theta_{i}\right)+f\left(\theta_{j}\right)}{6 \chi} \pi^{1 / 2}
$$

Fig. 10 compares the analytical expression to the FEM simulations. In this figure, the angle $\theta_{j}$ of the vector $\vec{c}$ that characterizes the bottom cylinder is set 
to 0 and $\pi / 4$ while the angle $\theta_{i}$ is varied between 0 and $\pi / 2$ by $\pi / 20$ steps, taking advantage of the $\pi / 2$ periodicity of the $f(\theta)$ function. Note that $\chi$ was used as a fitting parameter to minimize by a least square method the error between Eqs. (11) and $12\left(\mu_{\text {basal }}=110^{12} \mathrm{Pas}\right)$. A value $\chi \approx 16$ was found to minimize the error. Even though Fig. 10 only shows the comparison for $\theta_{j}=0$ and $\theta_{j}=\pi / 4$, the fit has been conducted on a much larger set of $\theta_{j}$ values $\left(11 \theta_{i} \times 11 \theta_{j}=121\right.$ pairs) for the four $a_{0} / R$ values studied here.

The match between Eqs. (11) and (12) is far from perfect with maximum error for the smallest $a_{0} / R$ value and $\theta_{j}=\pi / 4$ of the order of $20 \%$ and negligible errors for $\theta_{j}=0$. Still the comparison is satisfactory in that the general shape of the $f(\theta)$ function is well retrieved.

\section{Concluding remarks}

We have shown that the viscoplastic contact response between monocrystalline ice particles exhibits strong anisotropy. This anisotropy directly originates from the hexagonal structure of ice. When rotation is not hindered, the phenomenology of the indentation is rather complex, involving the propagation of basal slips and the formation of ice 'fragments' within the particle during loading. Localization of shear bands is the major strain mechanism. Light polarization and DIC are well suited to capture these strong heterogeneities that arise mainly parallel to the basal planes. These strain heterogeneities are coupled with a rotation of the $\vec{c}$ axis towards the loading axis.

When rotation is limited by a large contact area, the indentation evolution of two particles with arbitrary $\vec{c}$ axis orientation is more tractable. In that case, the simple analytical model presented here provides a means of extrapolating the contact response of strongly anisotropic ice particles. The simple forms of Eq. (3), and Eq. (8) have been partially validated by a combination of experiments on truncated cylinders and by 2D FEM calculations. In particular, the role of contact size and of the crystallographic disorientation between the particles are correctly rendered. 
It should be clear that the Newtonian law used here for single ice crystals is only a simplifying assumption which may not reflect the correct strain-rate dependency. Power-law exponent of 1.5 to 2.5 are typically mentioned in the literature [9, 20]. For polycrystalline ice, both Newtonian and non-Newtonian behaviors have been observed [42, 43]. In any case, it would be interesting to generalize this study to non-Newtonian behavior and investigate the effect of $n>1$ in Eq. $(5)$ on the shape of the $\tilde{\dot{h}}$ versus $\theta_{i}$ curves (Fig. 10).

As stated above, the proposed analytical model is only valid when rotation may be neglected. Fortunately, this assumption is appropriate in many cases that are relevant for firn at intermediate relative density (above 0.60). In that density range, the firn still exhibits a particulate structure with ice particles contacting each other. In the densifying firn, a representative ice particle is in contact with an increasing number of neighboring particles. Assuming a spherical shape, the coordination number should be larger than five for a relative density larger than 0.6. This should safely ensure a limited amount of rotation at the contact scale. Thus, we believe that the simple equations proposed here should be useful for applications where the viscoplastic anisotropy of the mutual indentation of ice particles needs to be taken into account. Such equations may be used in analytical models or in Discrete Element Method simulations that could predict firn densification with the anisotropy of ice crystals taken into account. Such models or numerical simulations should shed new light on the problem of pore closure and thus should improve understanding of ice core records of past atmospheric composition. In particular, we have demonstrated here that contacts between ice particles in the firn behave very differently depending on the orientation of particles. The firn microstructure, in the intermediate relative density range, should reflect somehow this contact network, with some contacts experiencing large deformation while others nearly none.

More generally, the methodology described here can be applied to other strongly anisotropic particulate materials such as magnesium, zinc, or titanium powders. The macroscopic behaviour of those important engineering materials is well described by a transverse isotropic law. The form proposed in Eqs. (1) 
and (2) remains valid. Depending on the relative weight of basal, prismatic or pyramidal gliding mechanisms, the values of the $\mu_{\text {basal }}$ and of the $\alpha$ and $\beta$ parameters in Eq. 22 may differ. Still, Eq. 6. offers a useful tool to model the collective behaviour of strongly anisotropic powders.

\section{References}

[1] B. Salm, Mechanical properties of snow, Reviews of Geophysics 20 (1) (1982) 1-19.

[2] T. Ebinuma, N. Maeno, Experimental studies on densification and pressuresintering of ice, Annals of Glaciology 6 (1985) 83-86.

[3] E. Arzt, The influence of an increasing particle coordination on the densification of spherical powders, Acta Metall. 30 (1982) 1883-1890.

[4] L. Arnaud, V. Lipenkov, J.-m. Barnola, M. Gay, L. Arnaud, V. Lipenkov, J.-m. Barnola, M. Gay, P. D. Modelling, Modelling of the densification of polar firn : characterization of the snow-firn transition, Annals of Glaciology 26 (1998) 39-44.

[5] M. M. Herron, C. C. Langway, Firn densification : an empirical model., Journal of Glaciology 25 (93) (1980) 373-385.

[6] R. B. Alley, Firn densification by grain-boundary sliding : a first model, Journal de Physique 48 (1987) 249-256.

[7] T. Theile, H. Lowe, T. C. Theile, M. Schneebeli, Simulating creep of snow based on microstructure and the anisotropic deformation of ice, Acta Mater. 59 (18) (2011) 7104-7113.

[8] S. R. du Roscoat, A. King, A. Philip, W. Ludwig, Analysis of Snow Microstructure by Means of X-Ray Diffraction Contrast Tomography, Advanced Engineering Materials 13 (2011) 128-135. 
[9] P. Duval, M. F. Ashby, I. Andermant, Rate-Controlling Processes in the Creep of Polycrystalline Ice, Journal of Physical Chemistry 87 (1) (1983) 4066-4074.

[10] V. F. Petrenko, R. W. Whitworth, Physics of Ice, OUP Oxford, 1999.

[11] R. L. Brown, A volumetric constitutive law for snow based on a neck growth model, Journal of Applied Physics 51 (1) (1980) 161-165.

[12] P. Hagenmuller, G. Chambon, M. Naaim, Microstructure-based modeling of snow mechanics : A discrete element approach, Cryosphere 9 (5) (2015) 1969-1982.

[13] A. Wautier, C. Geindreau, F. Flin, Numerical homogenization of the viscoplastic behavior of snow based on X-ray tomography images, The Cryosphere Discussions (December) (2016) 1-28.

[14] G. Durand, F. Gillet-Chaulet, A. Svensson, O. Gagliardini, S. Kipfstuhl, J. Meyssonnier, F. Parrenin, P. Duval, D. Dahl-Jensen, Change in ice rheology during climate variations - implications for ice flow modelling and dating of the EPICA Dome C core, Climate Of The Past 3 (1) (2007) $155-167$.

[15] C. Martín, G. H. Gudmundsson, H. D. Pritchard, O. Gagliardini, On the effects of anisotropic rheology on ice flow, internal structure, and the agedepth relationship at ice divides, Journal of Geophysical Research : Earth Surface 114 (4) (2009) 1-18.

[16] M. Montagnat, J. R. Blackford, S. Piazolo, L. Arnaud, R. A. Lebensohn, Measurements and full-field predictions of deformation heterogeneities in ice, Earth and Planetary Science Letters 305 (1-2) (2011) 153-160.

[17] M. Montagnat, P. Duval, Rate controlling processes in the creep of polar ice, influence of grain boundary migration associated with recrystallization, Earth and Planetary Science Letters 183 (1-2) (2000) 179-186. 
[18] N. Fletcher, The chemical physics of ice, Cambridge University Press, 1970.

[19] E. M. Schulson, P. Duval, Creep and Fracture of Ice, Cambridge University Press, 2009.

[20] J. Chevy, F. Louchet, P. Duval, M. Fivel, Creep behaviour of ice single crystals loaded in torsion explained by dislocation cross-slip, Philosophical Magazine Letters 92 (6) (2012) 262-269.

[21] J. Meyssonnier, A. Philip, A model for the tangent viscous behaviour of anisotropic polar ice, Annals of Glaciology (1996) 253-261.

[22] P. Mansuy, J. Meyssonnier, A. Philip, Localization of deformation in polycrystalline ice : Experiments and numerical simulations with a simple grain model, Computational Materials Science 25 (1-2) (2002) 142-150.

[23] A. Higashi, S. Koinuma, S. Mae, Plastic Yielding in Ice Single Crystals, Japanese Journal of Applied Physics 3 (10) (1964) 610-616.

[24] B. Storåkers, N. A. Fleck, R. M. McMeeking, The viscoplastic compaction of composite powders, J. Mech. Phys. Solids 47 (1999) 785-815.

[25] B. Storåkers, S. Biwa, P. P.-L. Larsson, Similarity analysis of inelastic contact, International Journal of Solids and Structures 34 (24) (1997) 30613083 .

[26] K. L. Johnson, Contact Mechanics, Cambridge University Press, 1985.

[27] http ://elmerice.elmerfem.org/.

[28] J. Baruchel, M. Di Michiel, T. Lafford, P. Lhuissier, J. Meyssonnier, H. Nguyen-Thi, A. Philip, P. Pernot, L. Salvo, M. Scheel, Synchrotron Xray imaging for crystal growth studies, Comptes Rendus Physique 14 (2-3) (2013) 208-220.

[29] P. Mansuy, J. Meyssonnier, A. Philip, Modelling the ice single-crystal viscoplastic behaviour, Springer Berlin Heidelberg, Berlin, Heidelberg, 1999, pp. $215-224$. 
[30] P. Mansuy, A. Philip, J. Meyssonnier, Localization of deformation in polycrystalline ice, Journal of Physics IV 11 (2001) 267-274.

[31] J. Schindelin, I. Arganda-Carreras, E. Frise, V. Kaynig, M. Longair, T. Pietzsch, S. Preibisch, C. Rueden, S. Saalfeld, B. Schmid, J.-Y. J.-Y. Tinevez, D. J. White, V. Hartenstein, K. Eliceiri, P. Tomancak, A. Cardona, K. Liceiri, P. Tomancak, C. A., Fiji : an open source platform for biological image analysis., Nature Methods 9 (7) (2012) 676-682.

[32] F. Grennerat, M. Montagnat, O. Castelnau, P. Vacher, H. Moulinec, P. Suquet, P. Duval, Experimental characterization of the intragranular strain field in columnar ice during transient creep, Acta Materialia 60 (8) (2012) $3655-3666$.

[33] T. Chauve, M. Montagnat, P. Vacher, Strain field evolution during dynamic recrystallization nucleation; A case study on ice, Acta Materialia 101 (2015) $116-124$.

[34] L. Allais, M. Bornert, T. Bretheau, D. Caldemaison, Experimental characterization of the local strain field in a heterogeneous elastoplastic material, Acta Met. Mater. 42 (11) (1994) 3865-3880.

[35] M. Bourcier, M. Bornert, A. Dimanov, E. Héripré, J. L. Raphanel, Multiscale experimental investigation of crystal plasticity and grain boundary sliding in synthetic halite using digital image correlation, Journal of Geophysical Research : Solid Earth 118 (2) (2013) 511-526.

[36] T. Chauve, M. Montagnat, F. Barou, K. Hidas, A. Tommasi, D. Mainprice, Investigation of nucleation processes during dynamic recrystallization of ice using cryo-EBSD, Phil.Trans.R.Soc.A 375 (2017) 20150345.

[37] R. A. Lebensohn, M. Montagnat, P. Mansuy, P. Duval, J. Meysonnier, A. Philip, Modeling viscoplastic behavior and heterogeneous intracrystalline deformation of columnar ice polycrystals Acta Materialia 57 (5) (2009) $1405-1415$. 
[38] R. W. K. Honeycombe, The plastic deformation of metals, 1984.

[39] F. Gillet-Chaulet, O. Gagliardini, J. Meyssonnier, M. Montagnat, O. Castelnau, A user-friendly anisotropic flow law for ice-sheet modelling, Journal of Glaciology 51 (172) (2005) 3-14.

[40] F. Gillet-Chaulet, O. Gagliardini, J. Meyssonier, T. Zwinger, J. Ruokolainen, Flow-induced anisotropy in polar ice and related ice-sheet flow modelling, Journal of Non-Newtonian Fluid Mechanics 134 (1-3 SPEC. ISS.) (2006) 33-43.

[41] O. Gagliardini, T. Zwinger, F. Gillet-Chaulet, G. Durand, L. Favier, B. De Fleurian, R. Greve, M. Malinen, C. Martín, P. Räback, J. Ruokolainen, M. Sacchettini, M. Schäfer, H. Seddik, J. Thies, Capabilities and performance of Elmer/Ice, a new-generation ice sheet model, Geoscientific Model Development 6 (4) (2013) 1299-1318.

[42] C. S. M. Doake, E. W. Wolff, Flow law for ice in polar ice sheets, Nature 314 (1985) 255-257.

[43] F. Gillet-Chaulet, R. C. A. Hindmarsh, H. F. J. Corr, E. C. King, A. Jenkins, In-situ quantification of ice rheology and direct measurement of the Raymond Effect at Summit, Greenland using a phase-sensitive radar, Geophysical Research Letters 38 (24) (2011) 1-6. 


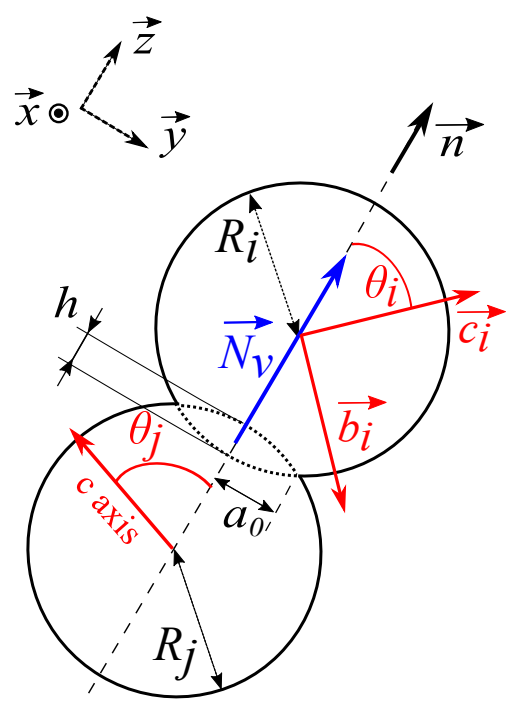

(a)

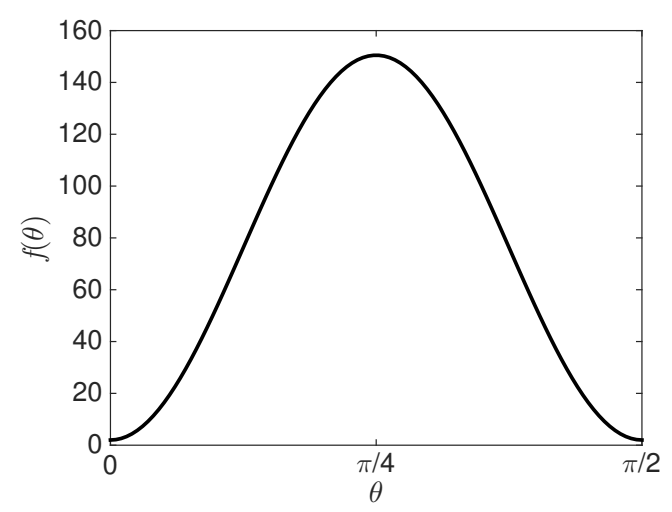

(b)

Figure 1: (a) Schematic representation of the anisotropic contact law between two indented spheres. $\left(\overrightarrow{b_{i}}, \overrightarrow{c_{i}}\right)$ is the local reference of the ice crystal $i . a_{0}$ is the initial contact radius (Eq. 7) (b) Evolution with the angle $\theta$ of orientation function $f$ given by Eq. 2 for $\alpha=1$ and $\beta=0.01$. 


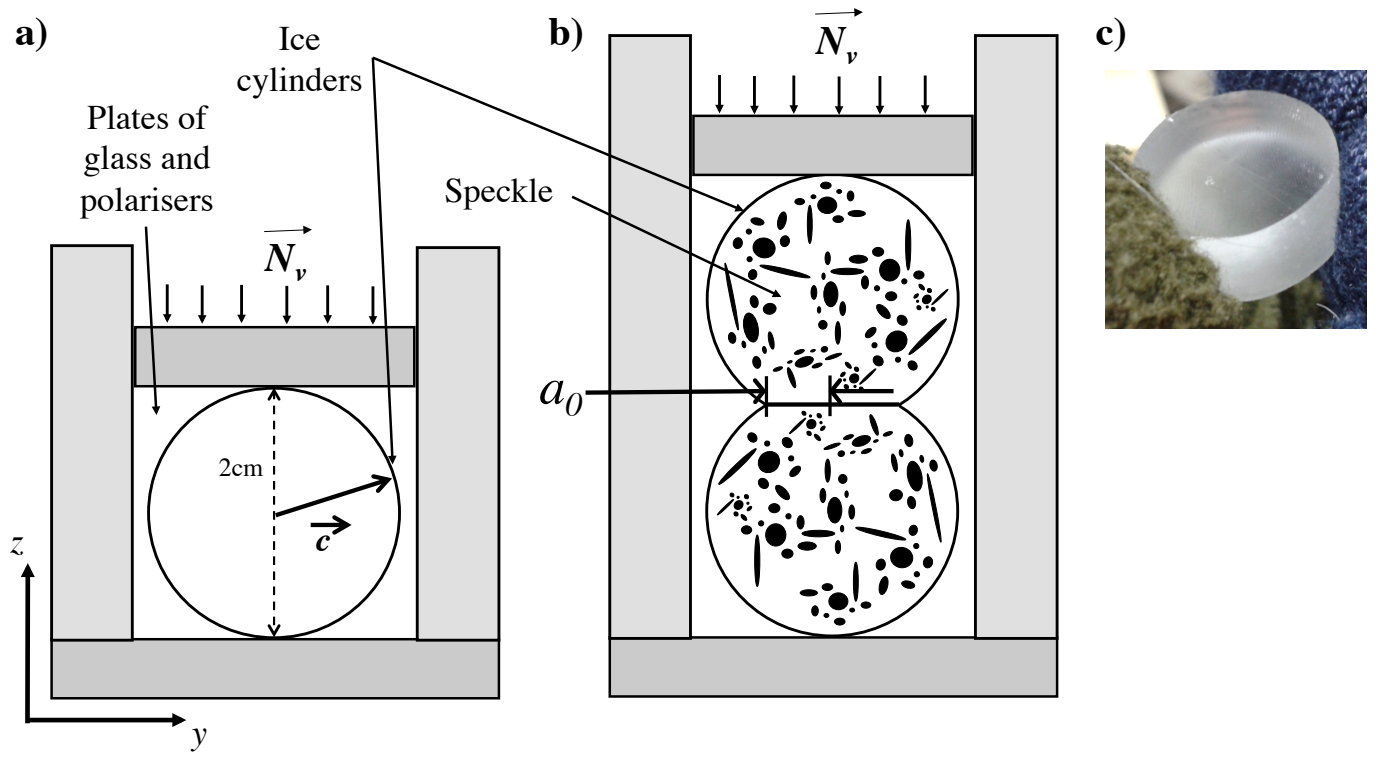

Figure 2: Experimental diametrical loading set-ups with $\vec{c}$ axis parallel to the planar surface of cylinders. Crossed polarisers may be placed in front and behind the set-up. a) Single cylinder configuration. b) Double cylinder configuration with initial contact length $2 a_{0}$. c) Photo of a typical monocrystalline ice cylinder. 


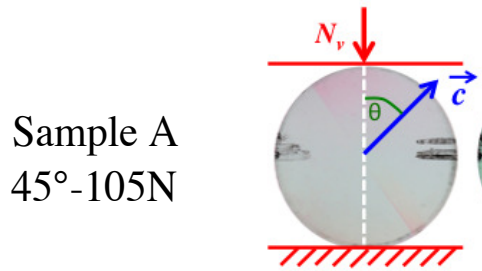

(A1)

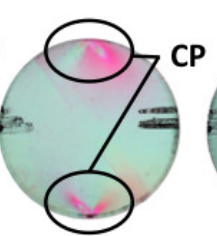

(A2)

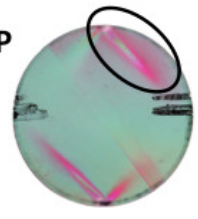

(A3)

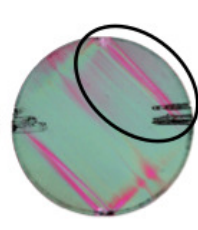

(A4)

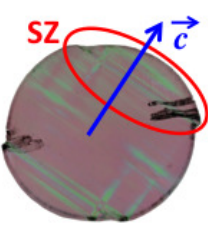

(A5)

\begin{tabular}{l|l|l|l|l|l}
- Before loading & $-\mathrm{t} 0$ & $-\mathrm{t}=4 \mathrm{~min}$ & $-\mathrm{t}=35 \mathrm{~min}$ & $-\mathrm{t}=82 \min$ \\
$-\theta=45^{\circ}$ & $-\theta=45^{\circ}$ & $-\theta=45^{\circ}$ & $-\theta=45^{\circ}$ & $-\theta=35^{\circ}$ \\
& $-\varepsilon_{z z}<0.3 \%$ & $-\varepsilon_{z z}<0.3 \%$ & $-\varepsilon_{z z} \approx 0.8 \%$ & $-\varepsilon_{z z}=5.7 \%$ \\
\hline
\end{tabular}

Sample B $60^{\circ}-109 \mathrm{~N}$

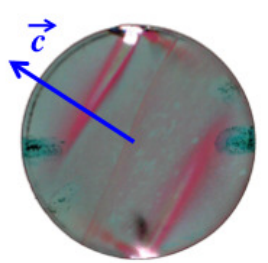

(B1)

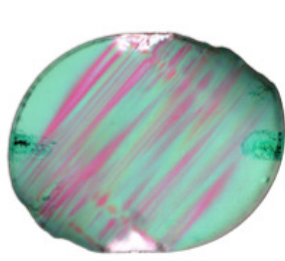

(B2)

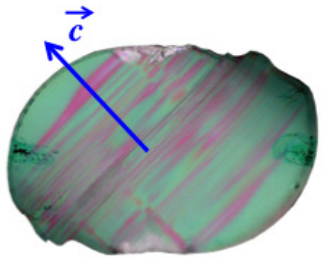

(B3)

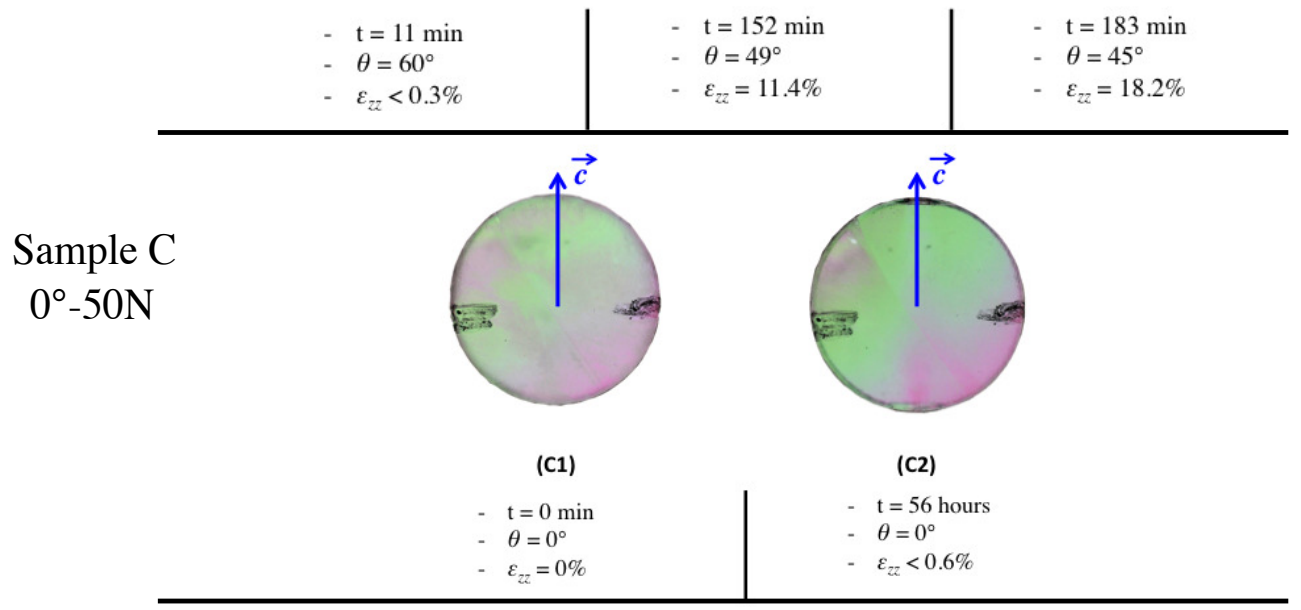

Figure 3: Evolution of the propagation of basal slips under polarized light for three different initial orientations $\left(\mathrm{A}: 45^{\circ} \pm 2^{\circ}, \mathrm{B}: 60^{\circ} \pm 2^{\circ}, \mathrm{C}: 0^{\circ} \pm 2^{\circ}\right)$ and various applied loads. Cylinder (A1) is the crystal just before loading. The dashed line indicates the loading direction. Strain localization is shown at Contact Points (CP) on (A2). (A3) and (A4) illustrate the propagation of slips through the crystal with the red areas spreading perpendicular to the $\vec{c}$-axis. (A4) shows the activation of multiple basal slip planes. (A5) shows an entire cap sliding (area SZ, Shearing Zone). Cylinder (B) exemplifies a condition for which the rotation is significant. Cylinder (C) exhibits negligible strain and rotation of the $\vec{c}$-axis even for very long times. 

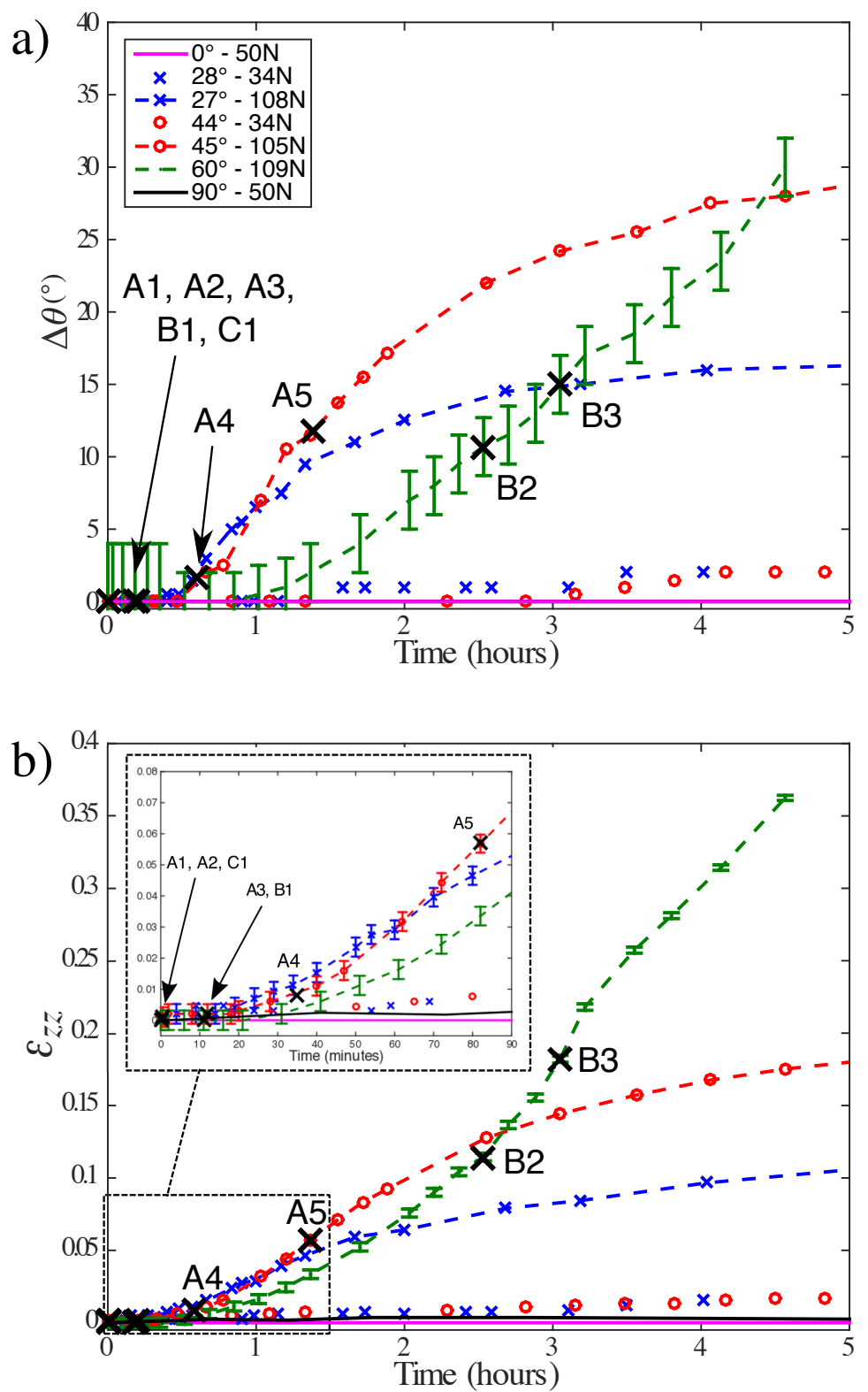

Figure 4: Evolution of the (a) rotation angle $\Delta \theta$ and (b) strain $\varepsilon_{z z}$ against time for monocrystalline cylinders of ice (single cylinder configuration). Samples are submitted to various loads and different initial angles of the $\vec{c}$-axis with respect to the load direction are tested. Strain is positive in compression. Error bars are shown only for sample B for clarity. Black markers A, B, C relate to observations in figure 3 Sample $\mathrm{C} 2$ is outside the time scale $(56 \mathrm{~h})$. The two samples corresponding to $\theta=0^{\circ}$ and $\theta=90^{\circ}$ lead to $\Delta \theta=0^{\circ}$. 

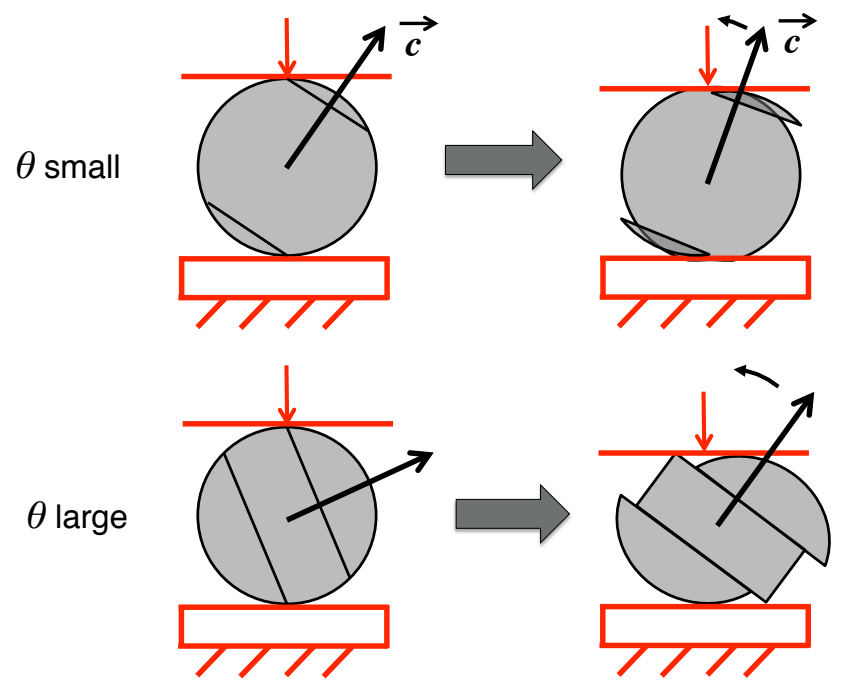

Figure 5: Schematics of the deformation process for the cylinders with a (a) small $\theta$ and a (b) large $\theta$. 


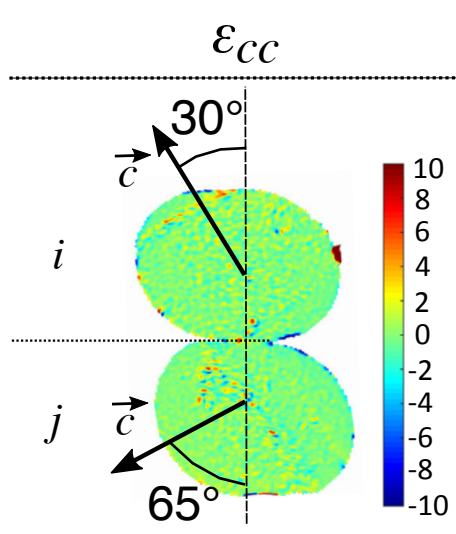

(a)

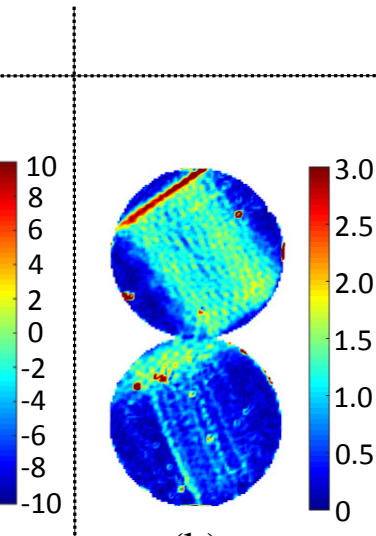

(b)

\section{$\varepsilon_{b c}$}

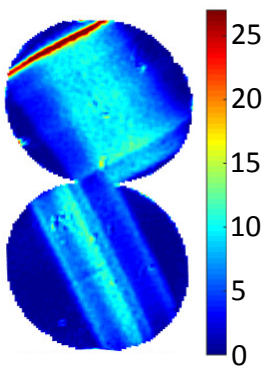

(c)

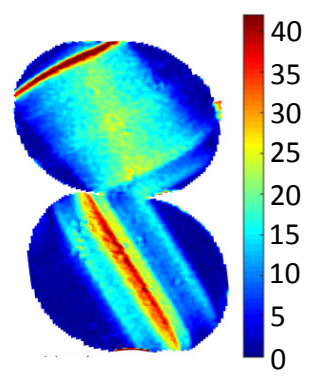

(d)

Figure 6: Strain maps (in \%) in the local reference $(\vec{b}, \vec{c})$ obtained by DIC analysis (see Fig. 1 1 ), considering that basal planes are parallel to the maximum shearing. Applied load : $53 \mathrm{~N}$, initial orientations : $\theta_{i}=30^{\circ}, \theta_{j}=295^{\circ}$. Initial contact size $: \frac{a_{0}}{R}=0.20$. (a) : strain $\varepsilon_{c c}$ at $200 \mathrm{~min}$. (b-d) : shear strain in the basal plane $\varepsilon_{b c}$ at different times : (b) $20 \mathrm{~min}$, (c) $120 \mathrm{~min}$ and (d) $200 \mathrm{~min}$. The gage length for this test is $504 \mu \mathrm{m} \pm 2 \mu \mathrm{m}$ and the resolution is $12.60 \mu \mathrm{m} /$ pixel $\pm 0.05 \mu \mathrm{m} /$ pixel (integration scheme 2 [35). 


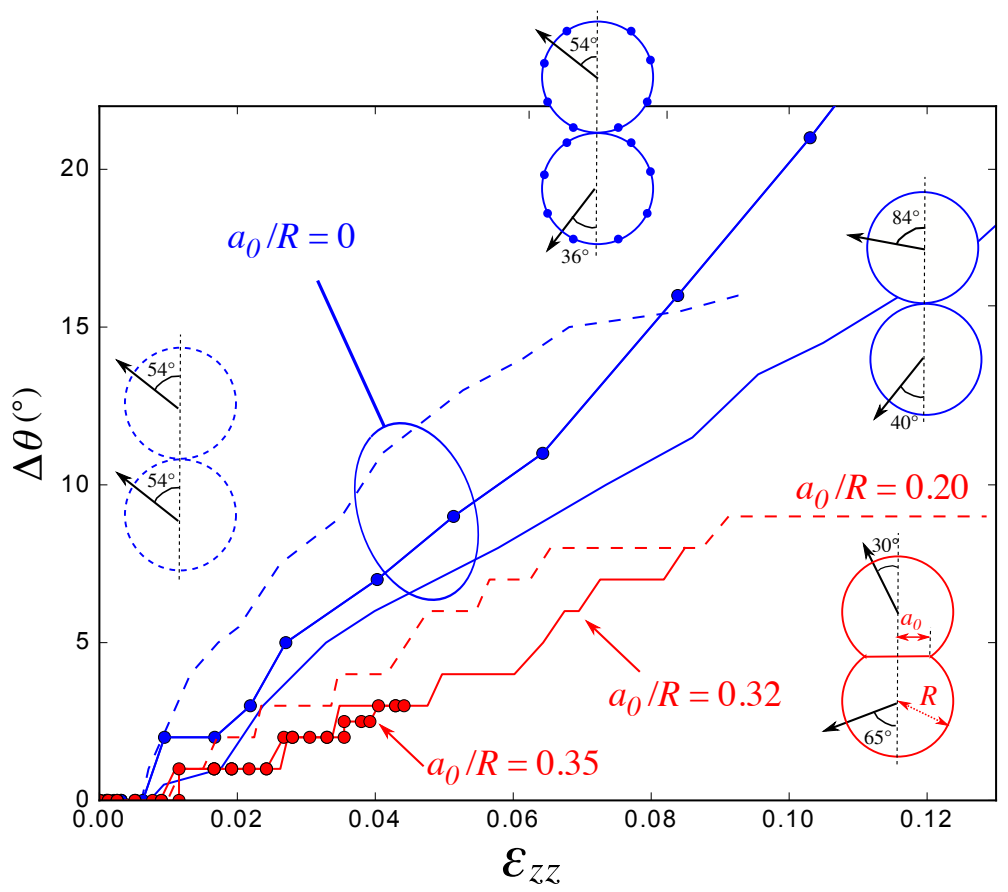

Figure 7: Evolution of the disorientation of $\theta$ with the indendation for the cylinder that turns the most in two-cylinders configuration experiments (load $54 \mathrm{~N}$ ). One can notice that maximum rotations for cylinders with initial neck size is lower than without neck. In other terms, the blue lines come from experiments in which cylinders rotate independently of one another in point contact configurations, while the red lines show that rotation is hindered because of the contact plane. 


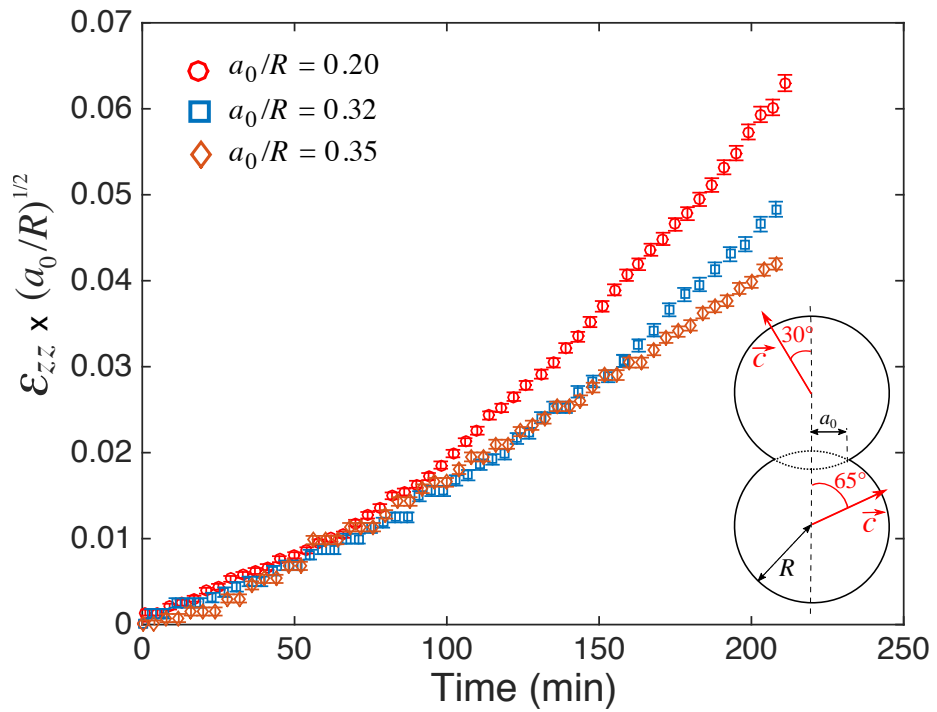

Figure 8: Evolution of the product $\varepsilon_{z z}\left(\frac{a_{0}}{R}\right)^{1 / 2}$ (with associated errorbars) against time for a creep load of $53 \mathrm{~N}$. Tests are carried out for a given set of $\left(\theta_{i}, \theta_{j}\right)$ angles (see inset) for three different values of $\frac{a_{0}}{R}$. Maximum macroscopic strains represented here are $\varepsilon_{z z}=0.141,0.084$ and 0.073 for $\frac{a_{0}}{R}=0.20,0.32$ and 0.35 , respectively. 
a)

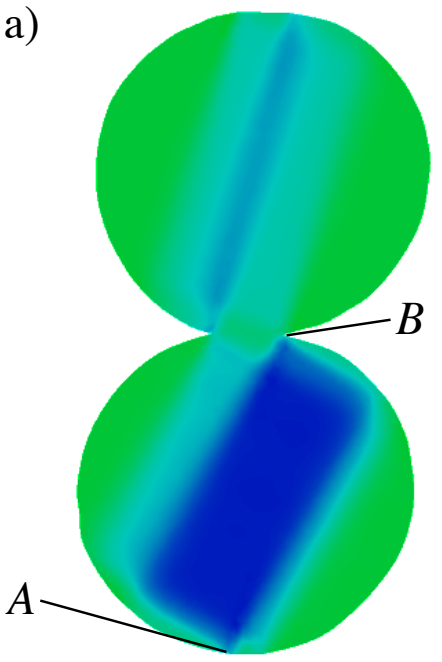

b)

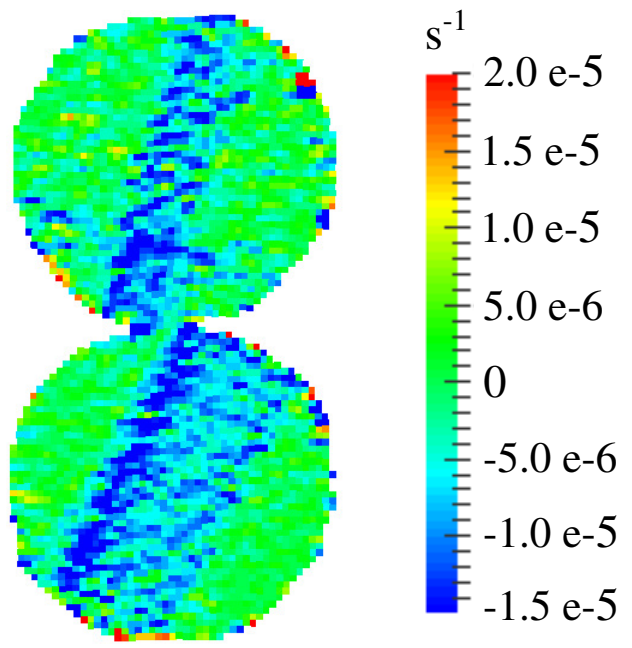

Figure 9: Strain rate field $\dot{\varepsilon}_{z z}\left(s^{-1}\right)$ at 80 minutes under $54 \mathrm{~N}$ for $\theta_{\text {initial }}(i)=75^{\circ}$ and $\theta_{\text {initial }}(j)=63^{\circ}$. a) Finite Element simulation results with $\mu_{\text {basal }}=110^{12}$ Pas and b) DIC results $\dot{\varepsilon}_{z z}$. The gage length for this test is $864 \mu \mathrm{m} \pm 2 \mu \mathrm{m}$ and the resolution is $21.60 \mu \mathrm{m} /$ pixel $\pm 0.05 \mu \mathrm{m} /$ pixel (integration scheme 2 [35). 

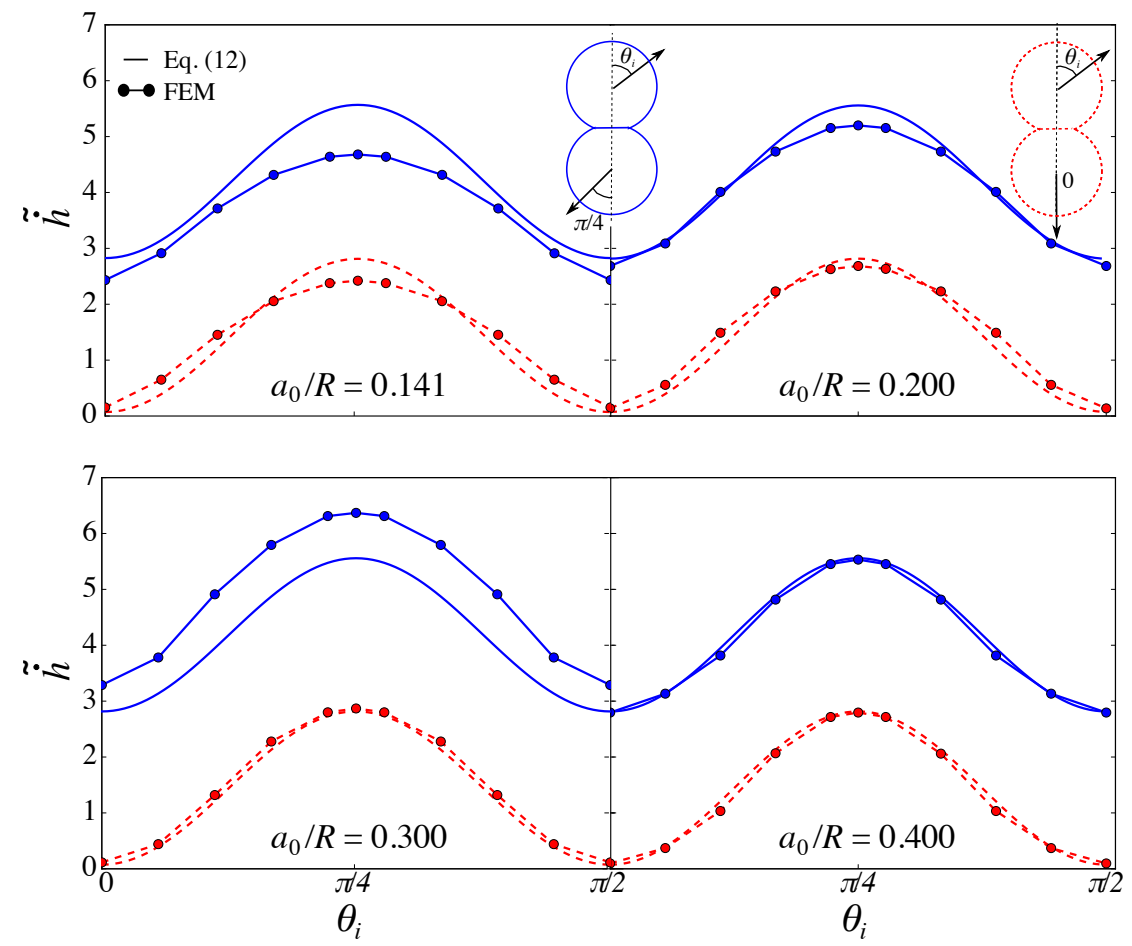

Figure 10: Evolution of the adimensional indentation rate $\tilde{\dot{h}}$ against $\theta_{i}$ for four values of $a_{0} / R$. Comparison of $\tilde{h}$ given by finite elements simulations (Eq. 11) ) and by the anisotropic contact model (Eq. 12 ) for $\theta_{j}=0$ (red dotted curves) and $\theta_{j}=\pi / 4$ (blue plain curves). All curves are $\pi / 2$ periodic. 